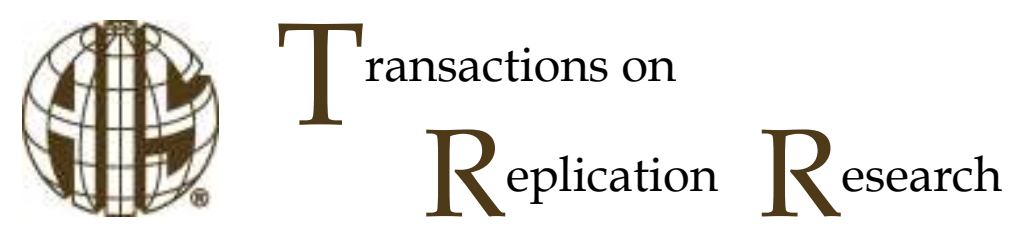

\title{
An Empirical Examination of Cognitive Absorption in a Computer-based Simulation Training Context
}

\author{
Vishal Shah \\ Business Information Systems- Central Michigan \\ University, Mt. Pleasant, USA \\ Shah3v@cmich.edu
}

\author{
Amr Soror \\ Information Systems and Decision Sciences- California \\ State University, Fullerton, USA \\ Asoror@fullerton.edu
}

\begin{abstract}
:
The purpose of this study is to conduct a conceptual replication of the model developed by Agarwal and Karahanna (2000) in the context of Enterprise Resource Planning (ERP) simulation. The model was tested using data collected from 251 students learning ERP in a simulated computer-based training environment. In general, results are consistent with the original study, where cognitive absorption positively influences perceived ease of use and perceived usefulness. Nonetheless, there were some notable differences. Unlike the original study, this replication study found that the cognitive absorption had no direct impact on perceived usefulness, but the effect was indirect via perceived ease of use underscoring the uniqueness of computer-based training environment. Further, perceived usefulness had no significant impact on use intention. Moreover, we found a significant positive relationship between perceived ease of use and perceived usefulness. The study controlled for age, gender, previous ERP experience, and business process experience.
\end{abstract}

Keywords: Cognitive Absorption, ERP, ERPSIM, Simulation

The manuscript was received 04/05/2017 and was with the authors 9 months for 2 revisions. 


\section{Introduction}

Motivated by the desire to understand users' behavior toward information technology (IT) and acknowledging IT's changing nature, Agarwal and Karahanna (2000) argued for the need to capture users' holistic experience with IT. To that end, Agarwal and Karahanna (2000) introduced cognitive absorption (CA) to Information Systems (IS) discipline. CA represents a multi-dimensional construct that not only integrates prior work focusing on users' intrinsic motivations toward using the technology but it also captures the users' extent of engagement with technology. As a result, Agarwal and Karahanna defined CA as a state of deep involvement with information technology where CA is reflected through five dimensions: a) temporal dissociation, which refers to the user's inability to register the passage of time while engaged in an interaction, b) focused immersion, which refers to the user's experience of total engagement where other attentional demands are ignored, c) heightened enjoyment, which refers to the pleasurable aspects of the interaction, d) control, which refers to the user's perception of being in charge of the interaction, and $e$ ) curiosity, which refers to the extent to which the experience arouses the user's sensory and cognitive curiosity.

Agarwal and Karahanna (2000) situated CA in a nomological network where individual traits such as personal innovativeness and computer playfulness represent antecedents of CA, while beliefs such as perceived ease of use and usefulness as well as intention to use IT in the future represent consequences of CA. The proposed relationships were tested and supported within the context of World Wide Web use among college students where the IT artifact used in their study represented a volitional technology that was widely used by the study population and was general in nature.

Agarwal and Karahanna (2000) suggested, as one of the possible implications of their study, that IS training programs could be designed to facilitate the engagement in a state of CA for potential users. To add, they argued that "Game-based training environments are more enjoyable (Venkatesh, 1999) and more likely to result in cognitive absorption, thus amplifying both beliefs about the instrumentality of the technology and its ease of use, as well as enhancing its adoption." (p. 688). The current study aims to shed more light on the role of $\mathrm{CA}$ in game-based training environments due to the unique nature of game-based training methods and the limited number of attempts examining CA as well as its potential implications in gamebased training contexts.

Compared to traditional training methods used in IS research (i.e., training methods that aim solely at disseminating knowledge to its users (e.g., concept-first or procedure-first)), game-based training programs not only provide adequate information to facilitate knowledge acquisition but also have the potential to be more intrinsically motivating (Venkatesh, 1999). The reason is that game-based training applications can offer a curiosity evoking and challenging training environment which makes the learning experience more enjoyable (Malone, 1981; Venkatesh, 1999) and might result in a higher level of cognitive absorption (Agarwal and Karahanna, 2000).

To summarize, in the current manuscript we aim to conceptually replicate Agarwal and Karahanna's (2000) work to examine the generalizability of their proposed model to a game-based training context. We focus specifically on computer game-based simulation training versions of work-related information.

Enactive learning, rooted in social cognitive theory (Bandura, 1989), is defined as "a form of observational learning that involves learning as a consequence of one's interaction with and feedback from the environment' (Leger et al., 2014, p. 273). Saying it differently, enactive learning is learning by doing and examining the consequences of one's actions, which provide prompt feedback and information to users to modify their actions if needed. Léger et al. (2012) reported that learning is perceived to occur more so during the enactive period (such as during a simulation of an IT training) as compared to other more direct instruction periods (such as a more formal presentation). The advantages of computer game-based simulation training are theorized to result primarily from deep involvement experienced by trainees when they actively engage in learning the work-related information systems via simulations (Sitzmann, 2011). Furthermore, calls have been made to conduct more research to gain further understating of enactive learning in IT/IS training (Sein et al., 1999; Leger et al., 2012; 2014).

Examining training contexts that have the potential to enhance cognitive absorption is of high interest because a state of cognitive absorption is likely to generate a more involved enactive learning experience, which can, in turn, enhance the acceptance and effective use of the focal information systems. To add, enactive training programs can perhaps be designed to induce neurophysiological states that would result in more efficient and better use of the technology. Such insights could open up new frontiers for advancing 
the development of more efficient, effective, and enjoyable training environments, and hence enhanced user acceptance and efficient use of technology.

A scant number of attempts have examined the full model introduced by Agarwal and Karahanna (2000), in the context of training and more specifically in a game-based training context as indicated by Table 1 . We found some differences in the results that could be attributed to the context of the study as the IS used in the prior studies may impact how CA might have manifested.

\begin{tabular}{|c|c|c|c|c|c|c|}
\hline \multicolumn{7}{|c|}{ Table 1. Summary of Prior Literature } \\
\hline $\begin{array}{l}\text { Author } \\
\text { (Year) }\end{array}$ & Context & $\begin{array}{l}\text { Purpose of the } \\
\text { system }\end{array}$ & $\begin{array}{l}\text { Type of } \\
\text { Use }\end{array}$ & Training & $\begin{array}{l}\text { Game } \\
\text { Based }\end{array}$ & $\begin{array}{l}\text { Key Findings of the } \\
\text { study }\end{array}$ \\
\hline $\begin{array}{l}\text { Midha } \\
\text { (2016) }\end{array}$ & $\begin{array}{l}\text { 3D virtual world } \\
\text { (Second Life } \\
\text { Platform) }\end{array}$ & $\begin{array}{l}\text { To support } \\
\text { knowledge-sharing } \\
\text { activities among } \\
\text { system users. }\end{array}$ & Voluntary & No & No & $\begin{array}{l}\text { CA's positive influence } \\
\text { on the intention toward } \\
\text { technology adoption } \\
\text { was mediated via } \\
\text { perceived ease of use } \\
\text { and usefulness. }\end{array}$ \\
\hline $\begin{array}{l}\text { Saadé } \\
\text { and Bahli } \\
\text { (2005) }\end{array}$ & $\begin{array}{l}\text { Internet-based } \\
\text { learning } \\
\text { systems (ILS) }\end{array}$ & $\begin{array}{l}\text { To provide access to } \\
\text { course materials and } \\
\text { practice exam } \\
\text { questions. }\end{array}$ & Mandatory & Yes & No & $\begin{array}{l}\text { CA's positive influence } \\
\text { on students' intentions } \\
\text { to use ILS is mediated } \\
\text { through ease of use } \\
\text { and perceived } \\
\text { usefulness. }\end{array}$ \\
\hline $\begin{array}{l}\text { Leong } \\
\text { (2011) }\end{array}$ & $\begin{array}{l}\text { Online learning } \\
\text { environment }\end{array}$ & $\begin{array}{l}\text { To disseminate the } \\
\text { material related to } \\
\text { courses as well as to } \\
\text { facilitater social } \\
\text { interactions among } \\
\text { users. }\end{array}$ & Mandatory & Yes & No & $\begin{array}{l}\text { CA mediates the } \\
\text { influence of a user's } \\
\text { perceived level of } \\
\text { social presence on } \\
\text { satisfaction with the } \\
\text { online learning } \\
\text { environment. }\end{array}$ \\
\hline $\begin{array}{l}\text { Bozoglan } \\
\text { et al. } \\
(2012)\end{array}$ & Internet Use & $\begin{array}{l}\text { To support myriad } \\
\text { activities ranging } \\
\text { from information } \\
\text { acquisition, } \\
\text { shopping, building } \\
\text { social relationships } \\
\text { to playing games. }\end{array}$ & Voluntary & No & No & $\begin{array}{l}\text { CA, along with } \\
\text { depression and internet } \\
\text { use, increased the level } \\
\text { of problematic internet } \\
\text { use. }\end{array}$ \\
\hline
\end{tabular}

To illustrate, CA in Saadé and Bahli (2005) study was manifested only through temporal dissociation, focused immersion, and heightened enjoyment but not through control and curiosity dimensions. Internetbased Learning System (ILS) used in Saadé and Bahli (2005) offered users with short tasks such as answering questions (multiple choice as well as true or false questions) or stop the session. Moreover, users' activities were very limited, and exploration was not possible. In contrast, CA in Midha (2016) was reflected through all dimensions proposed by Agarwal and Karahanna (2000) as the 3D virtual environment enabled its users to explore ample opportunities for knowledge exchange and to control their interactions not only with technology but with other virtual world users as well.

Furthermore, the relationship between CA and perceived ease of use was stronger in Midha (2016) relative to Saadé and Bahli (2005). This might be attributed to differences in how CA was manifested in each study due to IT designs. To elaborate, the presence of control and curiosity dimensions in Midha's (2016) study might have resulted in the stronger relationship. The sense of being in control of and the curiosity invoked by the possible interaction opportunities with a system (i.e., virtual world) could possibly reduce the perceived cognitive burden associated with the system use.

Some other attempts examining CA within different nomological networks were identified. For example, Leong (2011) examined in the context of the online learning environment the relationships among CA, users' interests in the topics taught as well users' perceived social presence and how these variables may predict 
students satisfaction. Finally, Bozoglan and colleagues (2012) drew our attention to the dark side of CA in the context of problematic internet among high school students. Prior work while informative in nature, did not examine Agarwal and Karahanna's (2000) proposed nomological network in a game-based training environment.

In our study, we focus on extending the generalizability of Agarwal and Karahanna's work (2000) to a gamebased training environment manifested in the use of simulation training software called ERPSIM (Cronan et al., 2012; Léger et al., 2011; Léger et al., 2012).

ERPSIM is designed to recreate a realistic business context in which trainees manage the main business processes within an organization using an Enterprise Resource Planning (ERP) system such as SAP. It could be thought of as a flight simulator for ERP systems. The main difference between ERPSIM and traditional SAP training is that ERPSIM simulates the passage of time and creates a simulated market which enables the users to experience the short term and long term consequences of their undertaken business decision. Participants enact a variety of business processes critical to ERP systems (e.g., buying, selling, and manufacturing). As participants encounter the consequences of their business actions in ERPSIM, they can fine-tune their future actions. Time simulation, along with the feedback on enacted business decisions, makes ERPSIM an effective training vehicle. Recent research results provide support for the authentic nature of this enactive ERP simulation (Léger et al., 2012). Moreover, ERPSIM could be considered as a "serious game" (Boughzala, 2014) where it leverages the fun dimension of games to promote the learning of serious concepts traditionally taught with conventional training methods. ERPSIM does so by allowing participants to interact with the simulation as well as receive and act on the feedback making it game-like. Consequently, ERPSIM can be considered as an immersive way to impart work-related business process training typical in an ERP system.

The rest of the manuscript is structured as follows: Research model, methods used, results, discussion, and conclusion.

\section{Research Model}

Our research model is the same as that of the original study except for the difference in the context and the nature of the technology. Figure 1 presents the research model, followed by the list of hypotheses in Table 2.

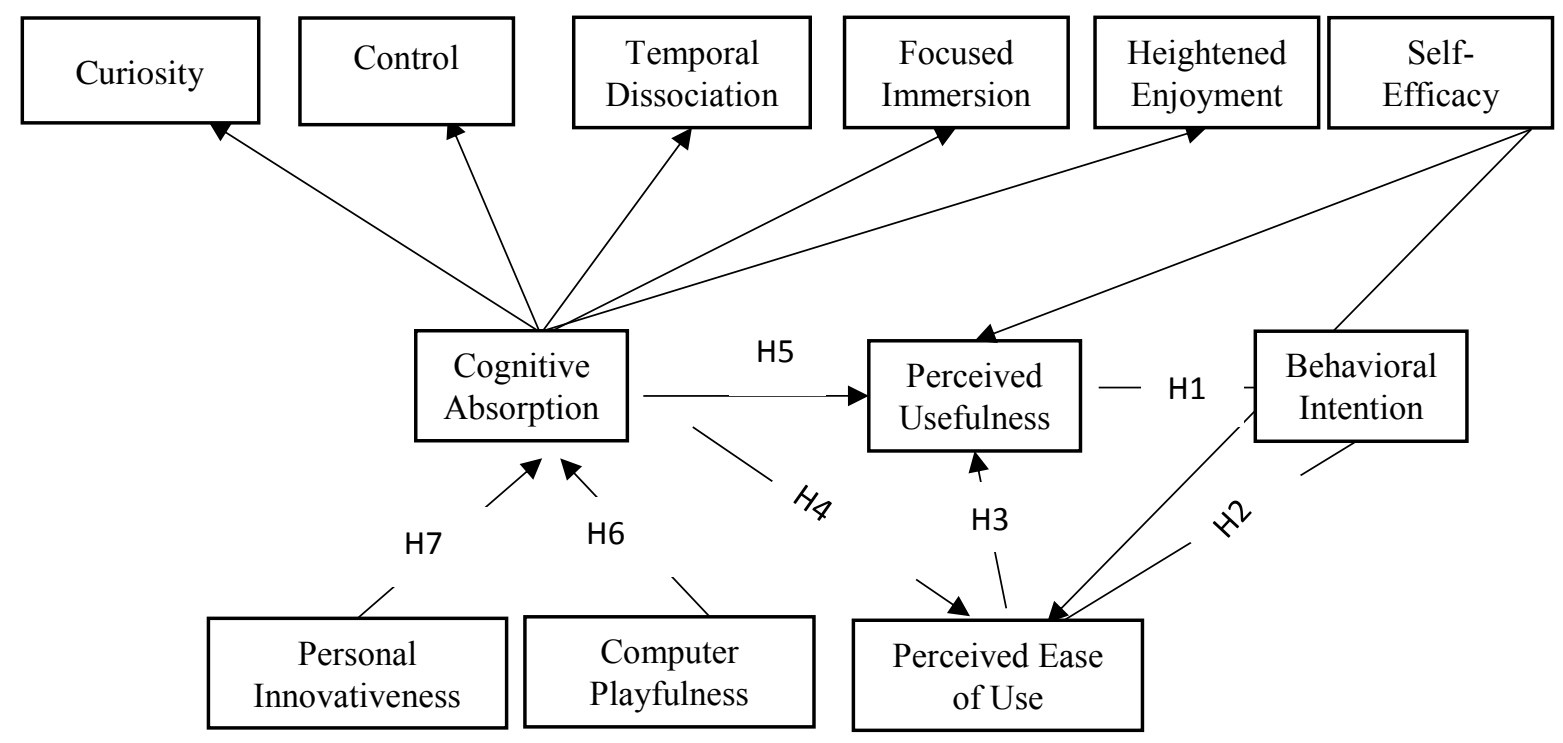

Figure 1. Research Model 
Table 2. Hypotheses

H1: Perceived usefulness of the information technology (ERPSIM) has a positive effect on behavioral intention to use the information technology (ERPSIM).

H2: Perceived ease of use of the information technology (ERPSIM) has a positive effect on behavioral intention to use the information technology (ERPSIM).

H3: Perceived ease of use of the information technology (ERPSIM) has a positive effect on the perceived usefulness of the information technology (ERPSIM).

$\mathrm{H} 4$ : After controlling for self-efficacy perceptions, cognitive absorption with the information technology (ERPSIM) has a positive effect on the perceived ease of use of the information technology (ERPSIM).

H5: After controlling for self-efficacy perceptions, cognitive absorption with the information technology (ERPSIM) has a positive effect on the perceived usefulness of the information technology (ERPSIM).

H6: Computer playfulness has a positive effect on cognitive absorption with the information technology (ERPSIM)

H7: Personal innovativeness has a positive effect on cognitive absorption with the information technology (ERPSIM)

\section{Method}

In this section, we describe the study context, measure, and related data analysis.

\subsection{Study Context and Sample}

We collected data for this project at a major public university in the Midwest. The participants were students in a senior-level business process class taught in an IS department in the College of Business. The class included ERP simulation as a part of the coursework. Students were provided with instructions in a reference guide before starting the simulation. The trainer showed them the transactions in an actual SAP system and then started each round of the simulation. The simulation ran for three rounds of simulated business quarters, 20 minutes each. A simulated business day is elapsed in one minute, and as a result, each simulated business quarter spanned 20 simulated business days. During each quarter, participants had to make and communicate decisions related to business processes (such as buying, selling, and producing a number of products) with other members of their fictitious company. Also, students had instant access to their own company's financial statements as well as periodic statements covering the overall market performance. After each quarter ended, the students had ten minutes to examine their performance relative to their peers and strategize for the next quarter. As a result, ERPSIM training is distinct from SAP traditional training wherein the ramifications of most business decisions will not be readily apparent until a later point in time in the future. For example, the impact of changing product prices on sales revenue will not be fully understood as the market typically takes time to adjust and respond to the changes made but in a simulated environment quicker feedback will be generated (i.e., in few minutes). The reference guide to the simulation can be found in the Appendix A. Appendix A details business processes (buying, selling, and producing) and related SAP ERP technical transaction codes. ${ }^{1}$

At the end of the ERP simulation, we distributed the survey to 300 students. After dropping incomplete and duplicate responses, we ended up with 251 complete usable responses which we base our analysis on. Students were awarded extra credit for participation in the survey. Students could also get the same credit if they opted to write a 5 page paper on ERP systems. However, we did not have any participants who opted to write the paper in lieu of taking the survey. Table 3 provides the demographic details of participants.

1 Details on ERP simulation: https://erpsim.hec.ca/en/about 


\begin{tabular}{|c|c|c|c|c|}
\hline \multicolumn{2}{|l|}{ Demographics } & Percentage & Min - Max & Mean \\
\hline \multirow[t]{2}{*}{ Gender } & Male & 64.94 & NA & NA \\
\hline & Female & 35.06 & NA & NA \\
\hline \multirow[t]{4}{*}{ Age } & $18-21$ & 58.56 & \multirow[t]{4}{*}{$18-64$} & \multirow[t]{4}{*}{22.67} \\
\hline & $21-25$ & 31.09 & & \\
\hline & $26-35$ & 8.36 & & \\
\hline & $>35$ & 1.99 & & \\
\hline $\begin{array}{l}\text { ERP/SAP } \\
\text { Experience (vears) }\end{array}$ & \multicolumn{2}{|l|}{ NA } & $0-5$ & 0.43 \\
\hline $\begin{array}{l}\text { Business Process Experience } \\
\text { (years) }\end{array}$ & \multicolumn{2}{|l|}{ NA } & $0-5$ & 1.06 \\
\hline
\end{tabular}

\subsection{Measures}

All the scales we used were adapted from the original study (Agarwal and Karahnna 2000). In the current study, we changed item wording to focus on the ERP simulation context.

\subsection{Data Analysis}

Following Agarwal and Karahanna (2000), we employed partial least squares (PLS) for structural equation modeling. PLS was deemed as an appropriate method; it is relatively robust in the face of restrictions on sample size and residual non-normality (Chin et al., 2003; 2010).

Table 4 summarizes the current study research design, sample frame, response rate, and statistical tools used and contrast them with the original study.

\begin{tabular}{|c|c|c|}
\hline \multicolumn{3}{|c|}{ Table 4. Overall Comparison of Two Studies } \\
\hline Factor & Current Study & Agarwal and Karahanna (2000) \\
\hline Research design & $\begin{array}{l}\text { Cross-sectional, self-reported } \\
\text { survey. } \\
\text { To reduce the length of the survey, } \\
\text { we captured the demographics as } \\
\text { well as experience with ERP and } \\
\text { Business processes before the ERP } \\
\text { simulation was administered. This } \\
\text { measure can also reduce survey } \\
\text { fatigue. }\end{array}$ & $\begin{array}{l}\text { Cross-sectional, self-reported } \\
\text { survey. } \\
\text { No measures were taken to reduce } \\
\text { survey fatigue. }\end{array}$ \\
\hline Sample Frame & $\begin{array}{l}\text { Senior level student in a business } \\
\text { process integration class in a } \\
\text { business school }\end{array}$ & $\begin{array}{l}\text { Junior level students in a statistics } \\
\text { class in a business school. }\end{array}$ \\
\hline Technology Usage & Mandatory & Voluntary \\
\hline Response Rate & $\begin{array}{l}\text { We distributed } 300 \text { surveys and had } \\
251 \text { complete and usable responses. } \\
\text { Thus, out response rate was } 83.67 \%\end{array}$ & $\begin{array}{l}\text { The original study did not report how } \\
\text { many surveys were distributed but } \\
\text { only reported how many were } \\
\text { returned. A total of } 288 \text { completed } \\
\text { responses were reported. }\end{array}$ \\
\hline Statistical Tool & Partial Least Squares (PLS) & Partial Least Squares (PLS) \\
\hline Controls & $\begin{array}{l}\text { Age } \\
\text { Gender } \\
\text { ERP Experience } \\
\text { Business Process Experience }\end{array}$ & $\begin{array}{l}\text { Age } \\
\text { Gender } \\
\text { Web Experience } \\
\text { PC Experience }\end{array}$ \\
\hline
\end{tabular}




\section{Results}

In the following section, we report the psychometric properties as well as the descriptive statistics of the used scales in our study as well as the results of the PLS measurement and structural models.

\begin{tabular}{|c|c|c|c|c|c|c|c|c|}
\hline \multirow[b]{2}{*}{ Constructs } & \multicolumn{2}{|c|}{ Composite Reliability } & \multicolumn{2}{|l|}{ AVE } & \multicolumn{2}{|l|}{ Mean } & \multicolumn{2}{|c|}{ Standard Deviation } \\
\hline & $\begin{array}{l}\text { Current } \\
\text { Study }\end{array}$ & $\begin{array}{l}A \quad \& \quad K \\
(2000)\end{array}$ & $\begin{array}{l}\text { Current } \\
\text { Study }\end{array}$ & $\begin{array}{l}A \text { \& K } \\
(2000)\end{array}$ & $\begin{array}{l}\text { Current } \\
\text { Study }\end{array}$ & $\begin{array}{l}\text { A \&K } \\
(2000)\end{array}$ & $\begin{array}{l}\text { Current } \\
\text { Study }\end{array}$ & $\begin{array}{l}A \quad \& \quad K \\
(2000)\end{array}$ \\
\hline CA:TD & 0.95 & 0.93 & 0.85 & 0.73 & 5.12 & 5.36 & 1.27 & 1.18 \\
\hline CA:FI & 0.84 & 0.88 & 0.56 & 0.60 & 4.94 & 4.76 & 1.25 & 0.98 \\
\hline $\mathrm{CA}: \mathrm{HE}$ & 0.92 & 0.93 & 0.74 & 0.77 & 4.90 & 5.15 & 1.33 & 1.06 \\
\hline $\mathrm{CA}: \mathrm{CO}$ & 0.94 & 0.83 & 0.85 & 0.60 & 5.09 & 5.33 & 1.24 & 0.93 \\
\hline CA:CU & 0.92 & 0.93 & 0.79 & 0.81 & 5.07 & 4.93 & 1.15 & 1.04 \\
\hline PIIT & 0.88 & 0.87 & 0.72 & 0.62 & 5.35 & 4.87 & 1.05 & 1.07 \\
\hline $\mathrm{CPL}$ & 0.96 & 0.94 & 0.83 & 0.67 & 5.66 & 4.69 & 1.00 & 1.04 \\
\hline SE & 0.89 & 0.91 & 0.77 & 0.51 & 5.62 & 5.34 & 1.01 & 1.03 \\
\hline PU & 0.97 & 0.93 & 0.76 & 0.76 & 5.62 & 5.43 & 1.26 & 1.01 \\
\hline PEOU & 0.94 & 0.90 & 0.79 & 0.71 & 4.93 & 5.34 & 1.28 & 1.03 \\
\hline $\mathrm{BI}$ & 0.94 & 0.97 & 0.83 & 0.90 & 5.33 & 6.35 & 1.13 & 1.07 \\
\hline
\end{tabular}

CA: Cognitive Absorption; TD: Temporal Dissociation; FI: Focused Immersion; HE: Heightened Enjoyment; CO: Control; CU: Curiosity; PIIT: Personal Innovativeness; CPL: Computer Playfulness; SE: Self-Efficacy; PU: Perceived Usefulness; PEOU: Perceived Ease of Use; BI: Behavioral Intention.

Table 5 illustrates the psychometric properties (reliability and validity) as well as descriptive statistics (mean and standard deviation) for each construct in comparison with Agarwal and Karahanna' (2000). Table 5 shows that similar to Agarwal and Karahanna (2000) study results; the used scales passed the thresholds recommended by the literature for reliability (reliability scores $>0.7$ ) and validity (AVE $>0.5$ ) (Nunnally and Bernstein, 1994). As for descriptive statistics, some similarities and differences could be noticed across the two studies, which could be attributed to the differences in the study contexts. We elaborate on our findings in the discussion section.

\subsection{Measurement Model Results}

Table 6 shows inter-construct correlation. The diagonal values represent the square root of Average Variance Extracted (AVE). AVE for each construct is greater than inter-construct correlations in the respective column (Fornell and Larcker, 1981), which indicates adequate discriminant validity. 


\begin{tabular}{|l|l|l|l|l|l|l|l|l|l|l|l|}
\hline \multicolumn{9}{|c|}{ Table 6. Inter-Construct Correlation } \\
\hline & CA:TD & CA:FI & CA:HE & CA:CO & CA:CU & PIIT & CPL & SE & PU & PEOU & BI \\
\hline CA:TD & 0.92 & & & & & & & & & & \\
\hline CA:FI & $.18^{* *}$ & 0.75 & & & & & & & & & \\
\hline CA:HE & $.33^{* *}$ & $.21^{* *}$ & 0.86 & & & & & & & & \\
\hline CA:CO & $.64^{* *}$ & $.33^{* *}$ & $.63^{* *}$ & 0.92 & & & & & & & \\
\hline CA:CU & $.37^{* *}$ & $.30^{* *}$ & $.75^{* *}$ & $.66^{* *}$ & 0.89 & & & & & & \\
\hline PIIT & 0.02 & 0.06 & 0.04 & 0.10 & 0.10 & 0.85 & & & & & \\
\hline CPL & 0.08 & $.45^{* *}$ & $.18^{* *}$ & $.22^{* *}$ & $.18^{* *}$ & -0.02 & 0.91 & & & & \\
\hline SE & 0.10 & $.15^{*}$ & 0.07 & $.18^{* *}$ & $.13^{*}$ & $.14^{*}$ & $.130^{*}$ & 0.88 & & & \\
\hline PU & 0.07 & $.37^{* *}$ & $.21^{* *}$ & $.17^{* *}$ & $.17^{* *}$ & -0.02 & $.75^{* *}$ & 0.12 & 0.87 & & \\
\hline PEOU & $.14^{*}$ & $.43^{* *}$ & $.20^{* *}$ & $.18^{* *}$ & $.24^{* *}$ & 0.09 & $.61^{* *}$ & $.13^{*}$ & $.59^{* *}$ & 0.89 & \\
\hline BI & $.22^{* *}$ & $.55^{* *}$ & $.37^{* *}$ & $.44^{* *}$ & $.48^{* *}$ & 0.05 & $.42^{* *}$ & $.13^{*}$ & $35^{* *}$ & $.39^{* *}$ & 0.91 \\
\hline
\end{tabular}

Note: ${ }^{*} p<.05^{* *}<0.01^{* *} p<0.001$

Diagonal Elements are the square root of the variance shared between the constructs and their measurement. CA: Cognitive Absorption; TD: Temporal Dissociation; FI: Focused Immersion; HE: Heightened Enjoyment; CO: Control; CU: Curiosity; PIIT: Personal Innovativeness; CPL: Computer Playfulness; SE: Self-Efficacy; PU: Perceived Usefulness; PEOU: Perceived Ease of Use; BI: Behavioral Intention.

Item loadings are shown in Table 7. Items adequately load on their respective constructs, further substantiating discriminant and convergent validity. Cross loadings of the original study are not reproduced here due to space constraints. Based on Tables 5, 6, and 7 we can deduce that both studies are similar from the point of view of consistency of measure, convergent, and discriminant validity. Finally, item level means and standard deviations for each construct for the current study are reported in Appendix B. 
Table 7. Item Loadings

\begin{tabular}{|c|c|c|c|c|c|c|c|c|c|c|c|}
\hline \multirow[b]{2}{*}{ Items } & \multicolumn{11}{|c|}{ Constructs } \\
\hline & $\begin{array}{l}\text { CA: } \\
\text { TD }\end{array}$ & $\begin{array}{l}\text { CA: } \\
\text { FI }\end{array}$ & $\begin{array}{l}\text { CA: } \\
\text { HE }\end{array}$ & $\begin{array}{l}\text { CA: } \\
\text { CO }\end{array}$ & $\begin{array}{l}\text { CA: } \\
\text { CU }\end{array}$ & PIIT & CPL & SE & PU & PEOU & $\mathrm{BI}$ \\
\hline CA:TD1 & 0.92 & 0.16 & 0.30 & 0.53 & 0.32 & -0.02 & 0.08 & 0.06 & 0.07 & 0.11 & 0.20 \\
\hline CA:TD2 & 0.92 & 0.16 & 0.29 & 0.62 & 0.32 & 0.02 & 0.09 & 0.09 & 0.07 & 0.11 & 0.19 \\
\hline CA:TD3 & 0.92 & 0.17 & 0.30 & 0.60 & 0.36 & 0.05 & 0.06 & 0.12 & 0.06 & 0.13 & 0.21 \\
\hline CA:TD4 & 0.92 & 0.21 & 0.34 & 0.59 & 0.37 & 0.03 & 0.06 & 0.01 & 0.07 & 0.15 & 0.19 \\
\hline CA:FI2 & 0.07 & 0.88 & 0.16 & 0.21 & 0.24 & 0.03 & 0.39 & 0.12 & 0.32 & 0.36 & 0.46 \\
\hline CA:FI3 & 0.17 & 0.92 & 0.14 & 0.28 & 0.24 & 0.06 & 0.39 & 0.14 & 0.33 & 0.38 & 0.48 \\
\hline CA:FI4 & 0.24 & 0.84 & 0.26 & 0.36 & 0.31 & 0.10 & 0.41 & 0.09 & 0.35 & 0.40 & 0.51 \\
\hline CA:HE1 & 0.37 & 0.24 & 0.94 & 0.65 & 0.68 & 0.06 & 0.17 & 0.08 & 0.16 & 0.18 & 0.35 \\
\hline CA:HE3 & 0.23 & 0.18 & 0.88 & 0.49 & 0.68 & 0.00 & 0.14 & 0.05 & 0.20 & 0.18 & 0.34 \\
\hline CA:HE4 & 0.32 & 0.19 & 0.96 & 0.60 & 0.72 & 0.06 & 0.18 & 0.03 & 0.21 & 0.20 & 0.34 \\
\hline $\mathrm{CA}: \mathrm{CO} 1$ & 0.59 & 0.29 & 0.57 & 0.93 & 0.60 & 0.13 & 0.21 & 0.16 & 0.14 & 0.17 & 0.39 \\
\hline $\mathrm{CA}: \mathrm{CO} 2$ & 0.58 & 0.30 & 0.57 & 0.90 & 0.60 & 0.11 & 0.19 & 0.10 & 0.17 & 0.18 & 0.39 \\
\hline $\mathrm{CA}: \mathrm{CO} 3$ & 0.60 & 0.32 & 0.60 & 0.92 & 0.62 & 0.06 & 0.21 & 0.14 & 0.16 & 0.15 & 0.40 \\
\hline CA:CU1 & 0.34 & 0.28 & 0.63 & 0.60 & 0.92 & 0.11 & 0.20 & 0.07 & 0.14 & 0.19 & 0.40 \\
\hline CA:CU2 & 0.34 & 0.33 & 0.58 & 0.58 & 0.91 & 0.11 & 0.14 & 0.15 & 0.16 & 0.27 & 0.47 \\
\hline CA:CU3 & 0.33 & 0.21 & 0.79 & 0.58 & 0.85 & 0.07 & 0.14 & 0.11 & 0.15 & 0.16 & 0.41 \\
\hline PIIT1 & 0.03 & 0.02 & 0.02 & 0.07 & 0.05 & 0.72 & -0.04 & 0.14 & -0.02 & 0.06 & 0.00 \\
\hline PIIT2 & 0.03 & 0.10 & 0.06 & 0.12 & 0.12 & 0.95 & 0.01 & 0.13 & 0.00 & 0.14 & 0.11 \\
\hline PIIT3 & -0.01 & 0.06 & 0.03 & 0.08 & 0.09 & 0.86 & -0.02 & 0.04 & -0.04 & 0.06 & 0.04 \\
\hline CPL1 & 0.07 & 0.42 & 0.16 & 0.22 & 0.18 & -0.05 & 0.89 & 0.16 & 0.62 & 0.55 & 0.39 \\
\hline CPL2 & 0.05 & 0.40 & 0.16 & 0.18 & 0.16 & -0.02 & 0.92 & 0.13 & 0.70 & 0.57 & 0.39 \\
\hline CPL3 & 0.07 & 0.41 & 0.17 & 0.20 & 0.16 & -0.02 & 0.92 & 0.11 & 0.70 & 0.58 & 0.34 \\
\hline CPL4 & 0.05 & 0.46 & 0.17 & 0.18 & 0.17 & 0.05 & 0.90 & 0.18 & 0.71 & 0.64 & 0.40 \\
\hline CPL5 & 0.11 & 0.38 & 0.14 & 0.21 & 0.14 & 0.00 & 0.90 & 0.19 & 0.68 & 0.55 & 0.41 \\
\hline SE1 & 0.08 & 0.06 & 0.05 & 0.14 & 0.11 & 0.13 & 0.06 & 0.77 & 0.08 & 0.06 & 0.04 \\
\hline SE2 & 0.12 & 0.16 & 0.07 & 0.20 & 0.10 & 0.09 & 0.03 & 0.79 & 0.03 & 0.05 & 0.14 \\
\hline SE3 & 0.11 & 0.18 & 0.09 & 0.19 & 0.16 & 0.16 & 0.12 & 0.81 & 0.09 & 0.10 & 0.18 \\
\hline SE4 & 0.02 & 0.08 & 0.03 & 0.07 & 0.08 & 0.07 & 0.21 & 0.88 & 0.17 & 0.20 & 0.11 \\
\hline
\end{tabular}

CA: Cognitive Absorption; TD: Temporal Dissociation; FI: Focused Immersion; HE: Heightened Enjoyment; CO: Control; CU: Curiosity; PIIT: Personal Innovativeness; CPL: Computer Playfulness; SE: Self-Efficacy; PU: Perceived Usefulness; PEOU: Perceived Ease of Use; BI: Behavioral Intention.

Similar to Agarwal and Karahanna (2000), our study followed a cross-sectional study design and relied on self-reported data. As a result, there is a potential for common method bias. Common method bias represents a concern as overlooking its presence might potentially impact path coefficients (Podsakoff et al., 2003). To address this limitation appearing in Agarwal and Karahanna (2000), we assessed the presence of common method bias in our study via multiple techniques: Harmon's one-factor test via exploratory factor analysis (Podsakoff and Organ, 1986), examination of the correlation between constructs within the model (Pavlou et al., 2007), and a structural equation model (Liang et al., 2007).

The rationale for Harmon's one-factor test is that if common method bias poses a serious threat to the analysis and interpretation of the data, a single latent factor will emerge accounting for the majority of the manifest variables (Podsakoff and Organ, 1986). Results from this procedure yielded 11 factors, which accounted for $78.06 \%$ of the variation, with the first factor only accounting for $24.83 \%$, indicating that common method bias does not pose a serious threat in the current study (Sanchez et al., 1995). Next, we 
examined the correlation between first-order constructs in the correlation matrix (Table 5). Evidence of common method bias should have resulted in extremely high correlations ( $\left.r^{2}>.90\right)$ (Pavlou et al., 2007). In our analysis, the correlations did not indicate significant excessive correlations (largest correlation of 0.75 ) providing further support for the lack of significant common method bias in our analysis. Finally, we utilized the Liang et al. (2007) common method bias approach for a single-method factor within PLS. Liang's approach estimates the common method bias based on the strength of the loading between the common factor (obtained by pooling all constructs) and each individual items. When estimating the model including the common method factor (a) none of the original results change in their direction or significance, (b) the loadings of the common method factor on each indicator item are low and non-significant, and (c) the loadings of the substantive items on their respective constructs are all significant with greater magnitudes than the method factor loadings. Additionally, we examined the squared factor loadings of both the common method factor and the substantive construct indicators to determine the average variance explained for each construct. For our sample, the average explained variance by the substantive construct indicators was 0.79 , while the average method-based variance explained less than 0.01 . Together, the multiple tests used indicate that common method bias is not a significant concern within our study.

\subsection{Structural Model Results}

Figure 2 shows the structural model with 1000 iterations of bootstrapping in SmartPLS

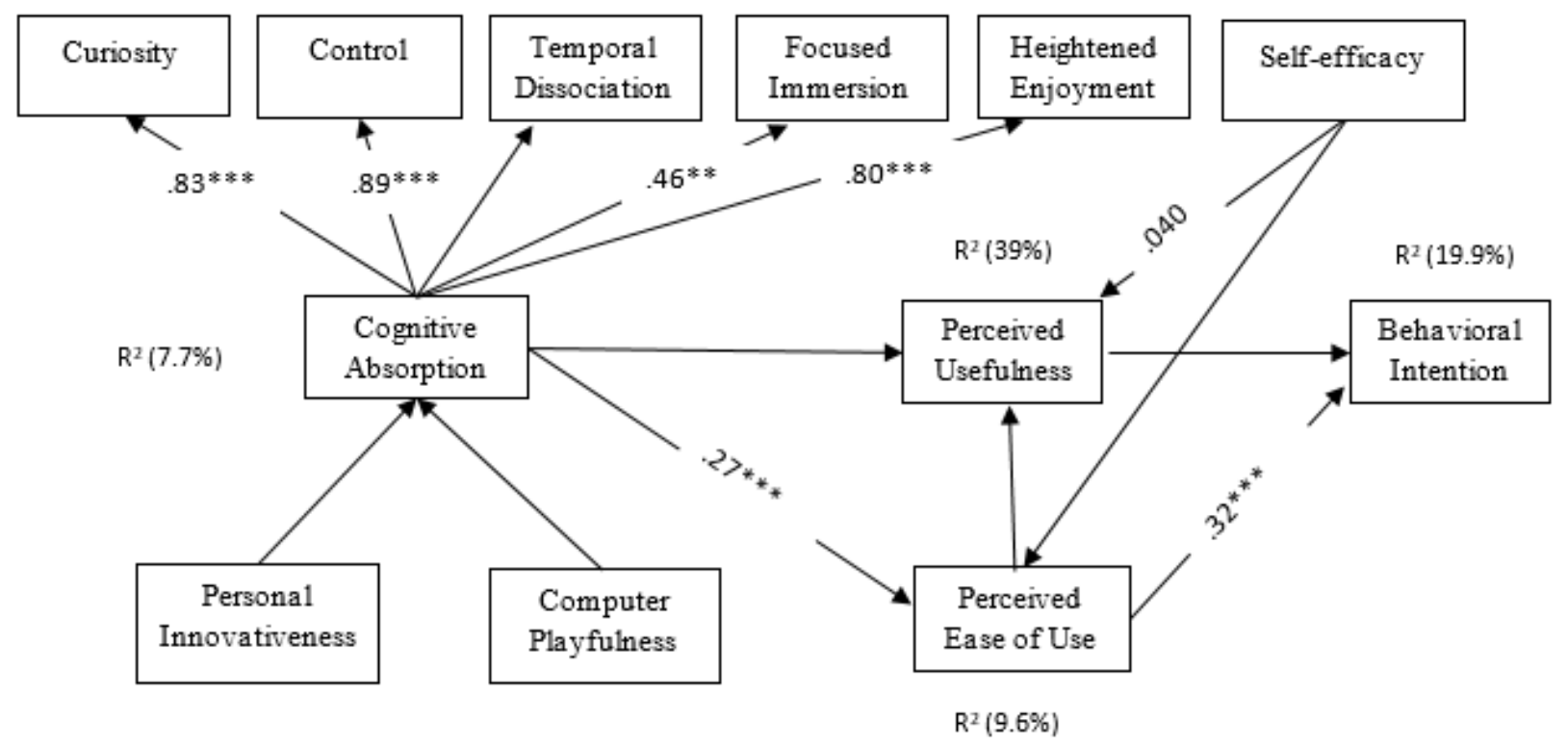

Note: ${ }^{*} p<.05^{* *}<0.01^{* * *} p<0.001$

Figure 2. Structural Model

As Figure 2 indicates, all but two hypothesized path coefficients were significant with the p-value of 0.05 . After controlling for self-efficacy, cognitive absorption had a significant direct effect on perceived ease of use but not on perceived usefulness. Personal innovativeness had no significant effect on cognitive absorption. Like the original study, we controlled for age, gender and prior experience with the used platform to eliminate confounding results. In agreement with the findings of the original study, none of the control variables were significant. Comparison of the current model's path coefficients results with those of Agarwal and Karahanna (2000) is shown in Table 8. 


\begin{tabular}{|l|l|l|l|l|}
\hline \multicolumn{5}{|c|}{ Table 8. Structural Model Results and Comparison with Agarwal and Karahanna (A\&K) (2000) } \\
\hline Path & A \&K (2000) & Support & Current Study & Support \\
\hline H1: PU $\rightarrow \mathrm{BI}$ & $0.48^{* * *}$ & Yes & $0.15^{*}$ & Yes \\
\hline H2: PEOU $\rightarrow \mathrm{BI}$ & $0.31^{* * *}$ & Yes & $0.32^{* * *}$ & Yes \\
\hline H3: PEOU $\rightarrow$ PU & 0.196 & No & $0.59^{* * *}$ & Yes \\
\hline H4: CA $\rightarrow$ PEOU & $0.59^{* * *}$ & Yes & $0.27^{* * *}$ & Yes \\
\hline H5: CA $\rightarrow$ PU & $0.52^{* * *}$ & Yes & 0.06 & No \\
\hline H6: CPL $\rightarrow \mathrm{CA}$ & $0.360^{* *}$ & Yes & $0.26^{* * *}$ & Yes \\
\hline H7: PIIT $\rightarrow \mathrm{CA}$ & $0.406^{* *}$ & Yes & 0.10 & No \\
\hline
\end{tabular}

Note: ${ }^{*} p<0.05:{ }^{* *} p<0.01 ;{ }^{* \star *} p<0.001$ PU: Perceived Usefulness; BI: Behavioral Intention; PEOU: Perceived Ease of Use; CA: Cognitive Absroption; CPL: Computer Playfulness; PIIT: Personal Innovativeness; TD: Temporal Dissociation (CA).

Table 9 shows the variance explained in the hypothesized model for relevant constructs in our study and compares it with the results from Agarwal and Karahanna (2000). Overall, the model explained less variance in the relevant constructs in our study versus the original study. For example, the model explained $19.9 \%$ variance in behavioral intention compared to $48 \%$ in the original study.

\begin{tabular}{|l|l|l|}
\hline \multicolumn{3}{|c|}{ Table 9. Explained Variance and Comparison with Agarwal and Karahanna (2000) } \\
\hline Dependent Variable & Agarwal \& Karahanna (2000) & Current Study \\
\hline CA & $42.1 \%$ & $7.7 \%$ \\
\hline PU & $46.2 \%$ & $39 \%$ \\
\hline PEOU & $46 \%$ & $9.6 \%$ \\
\hline BI & $48 \%$ & $19.9 \%$ \\
\hline
\end{tabular}

CA: Cognitive Absorption; PU: Perceived Usefulness; PEOU: Perceived Ease of Use. BI: Behavioral Intention.

\section{Discussion}

The objective of this manuscript is to conduct a conceptual replication of the work carried out by Agarwal and Karahanna (2000) in the context of game-based simulation training environments such as ERPSIM. Before delving into our findings, we would like to discuss the limitations of our study.

Like any other study, our work is subject to its limitations. Our study was cross-sectional in nature, a longitudinal study design with data collected at multiple points of time may result in different findings. Also, we examined common method bias in our work by utilizing available statistical tests suggested in the discipline (e.g., Podsakoff and Organ, 1986; Liang et al., 2007), but nonetheless we acknowledge that our results may be subject to common method bias which might be undetected by the used tools (see for a review Chin et al., 2012). Finally, the generalizability of our study results is limited by the IT artifact we used, our study context, and the sample. Future research is encouraged to examine the generalizability of our results to voluntary training contexts including employees as participants and using different simulation technology such as virtual or augmented reality.

We would like to proceed by discussing similarities and differences between the findings of our work and Agarwal and Karahanna's (2000) findings with respect to the measures used as well as model results. As for the measures used, similar to Agarwal and Karahanna (2000), adequate reliability was reported with a minimum composite reliability coefficient of 0.84 . Also, reported items loaded adequately on their respective constructs. Yet, the reported means of the main constructs in our sample showed some differences that could be attributed to the nature of the study's context (Table 5). For example, the mean level of PEOU, BI as well as CA dimensions such as control, heightened engagement, and temporal dissociation were significantly lower in our study relative to Agarwal and Karahanna (2000) at alpha less than 0.05 . This could be explained by comparing the context of our study to that of Agarwal and Karahanna's (2000) study. On the one hand, due to the mandatory training context, in our study, users had clear sets of instructions with clear objectives to be achieved within the training period. On the other hand, the World Wide Web use context was instruction free and had no clear dictated objective behind the use of technology. Consequently, the objective behind using the web could be anywhere along the spectrum of purely hedonic versus purely utilitarian use. To add, in our study, the technology was freshly introduced to the users, while in Agarwal and Karahanna (2000) the users had long stable experience with the platform. Finally, one can expect users to have better (i.e., higher) attitudes toward adopting a volitional technology versus mandatory technology (Venkatesh and Davis, 2000) and hence higher BI in the World Wide Web use context versus ERPSIM use 
context. To summarize, we can expect users to garner higher PEOU, higher engagement, higher control and temporal dissociation and BI with volitional technology use compared to mandatory technology use.

Notwithstanding the above explanation, our study sample reported significantly higher levels of self-efficacy, personal innovativeness, and computer playfulness relative to Agarwal and Karahanna (2000) at alpha less than 0.05 . This could be attributed to study participants' nature as well as the nature of the medium used for training. Senior-level IS students having a diversity of encounters with different technologies through their college education might have built higher levels of self-efficacy relative to junior level students enrolled in a statistics class sampled in the original study. Moreover, the ERPSIM medium used for training was a unique medium as it provided not only instructions but a chance to implement the instructions through roleplaying, simulating the passage of time, and providing prompt feedback. Thus, the ERPSIM could better leverage computer playfulness and personal innovativeness compared to World Wide Web use.

As for our finding pertaining to testing the nomological network of cognitive absorption presented by Agarwal and Karahanna (2000), we conclude that it was supported, in general, in the game-based training context. Although in our study the independent variables had lower ability to explain the variances in the dependent variables as reflected by $\mathrm{R}^{2}$ examined in Table 9 , it is possible to reach a state of cognitive absorption while interacting with computer-based simulation games for training. Moreover, we found that CA toward IS was exhibited through the five dimensions theorized by Agrawal and Karhanna (2000) of temporal dissociation, focused immersion, heightened enjoyment, control, and curiosity. Yet, CA manifestation through focused immersion dimension was much lower in our current study relative to Agrawal and Karahanna (2000). Also, it was lower than manifestations of CA through the other four dimensions. The difference can possibly be due to the different context of the study as well as the fact the participants were blind to ERPSIM before the simulation was administered, whereas participants in the original study were concerned with more generic and well-known focal technology (i.e., World Wide Web). For example, the relatively lower loading on CA focused immersion dimension could be attributed to the need of the users to communicate their business decisions to and coordinate with other members of their fictitious companies. As a result, while users were engaged with ERPSIM, other attentional demands (such as communicating with other players outside of the system) were also at play. It may have prevented focused immersion from developing to the extent that it did in the original study. To add, Agarwal and Karahanna (2000) examined the possible direct effect of CA on $\mathrm{BI}$ as a post-hoc analysis. We followed their steps and found that similar to the original study, CA plays a significant direct role in the formation of $\mathrm{BI}$ in game-based training context along with TAM variables (PEOU and PU). Furthermore, the inclusion of the direct path from CA to BI improved the overall explained variance in $\mathrm{BI}$ from $19.9 \%$ to $36.2 \%$ while it did not change the nature or significance of the other results while increasing. The post-hoc analysis is reported in Appendix C. In the current study, from Table 8 it is clear that the research model results differed from Agarwal and Karahanna's original findings in the following ways: a) personal innovativeness was not a significant predictor for cognitive absorption, b) cognitive absorption did not directly influence perceived usefulness, and c) perceived ease of use was found to impact perceived usefulness significantly.

For the first distinct finding, it could be the case that in a learning environment, a well-established structure is valued more than innovativeness to achieve cognitive absorption. Moreover, other factors may play a role in fostering cognitive absorption in the ERPSIM use context. For example, given that in the training environment, the participants may have interacted with each other, and these social interactions may have played a role in achieving cognitive absorption, and the need to recruit personal innovativeness could have been downplayed. Innovative solutions could be learned from participants, hence bypassing the need for personal innovation.

For the second distinct finding, given the immersive and interactive nature of the computer-based simulation game, cognitive absorption could possibly drive perceived ease of use of the technology with stronger impact relative to perceived usefulness. Based on self-perception theory (Bem, 1967), cognitive absorption can predispose the user to perceive that technology must have been easy to use as this perception can facilitate entering a state of immersion. However, it does not mean the technology was necessary useful. To elaborate, during the simulation users engaged in role-playing and assumed roles of managers of the fictitious company, buying, producing, and selling fictitious products in a fictitious simulated market. Such exposure can enhance the state of engagement among users, but it does not directly influence the perceived usefulness of the system. Nonetheless, cognitive absorption can influence the perceived usefulness of 
technology through its ease of use. Such an indirect effect was confirmed in our post-hoc analysis. ${ }^{2}$ Another interpretation could be based on the construal level theory perspective (Fiedler, 2007; Trope et al., 2010) where psychological distance influences the way people regard or construe an object or activity. Psychological distance could be understood in terms of its four dimensions: time, spatial, social, and hypothetical. On the one hand, people tend to develop concrete mental construals or low-level mental representations that reflect on contextual details of an object or activity when they perceive low psychological distance from that object or activity (i.e., occurring in the near future, close to the person, very likely to occur, and may occur to people like one's self). On the other hand, people tend to develop abstract mental construals or high-level mental representations that are more decontextualized and general when they perceive high psychological distance from that object or activity (i.e., occurring further into the future, far from the person, very unlikely to occur, and occur to people unlike one's self). Moreover, abstract or high-level construals have been found to emphasize the desirability of the target object or activity (e.g., usefulness), while concrete or low-level construals emphasize feasibility concerns toward performing an activity (e.g., ease). As a result, perceived usefulness of could be considered as a distal (abstract) construal level perception of the technology because the utility of ERP systems is likely to be realized at a later time (i.e., in the future). However, perceived ease of use could be considered as the more proximal (concrete) level perception of the technology. Similarly, we believe that perceived cognitive absorption is more of a proximal (concrete) level perception of technology given its development based on close and direct engagement (i.e., low experiential distance) (Fiedler et al., 2012). Consequently, we would expect representations at the same level to have stronger impacts on each other relative to their impact on representations at a more abstract level.

One more explanation for this finding may lay in the demographics of the study. As we can see from Table 3 , about $88 \%$ of the participants were between the ages 18 to 25 years. Given the age of participants, it is a reasonable assumption that they may be more absorbed with those aspects of the simulation that lead to ease of use of the technology rather than its usefulness. It is possible that perceived usefulness may not be relevant to the participants, as they may not see ERP simulation as a useful tool to advance their overall performance in the college. Later in the article, we summarize lessons we learned for future researchers interested in replication research.

For the third distinct finding, our results were consistent with the general technology adoption literature pertaining to the relationship between perceived usefulness and ease of use (Davis et al., 1989). Agarwal and Karahanna's (2000) insignificant findings could be attributed to the relatively longer experience of their study participants with the use of the technology (World Wide Web) where the longer the experience, the weaker the relationship between perceived ease of use and usefulness (Hess et al., 2014). In our study, the participants did not have prior experience using the ERPSIM; thus the easier the technology is to use, the better the chances the user would explore the different features of the technology and evaluate its usefulness. Finally, the majority of our study participants could be considered as digital natives or millennials, characterized by being confident with respect to new technology adoption and hence are more likely to explore and appreciate the usefulness of the features the technology has to offer (Chung et al., 2010). Thus, participants value the usefulness. However, the significance comes indirectly through ease of use rather than a direct assessment of simulation utility.

We would like to shed light on some of our findings in contrast to prior studies such as Midha (2016) and Leong (2011). For example, our study findings, similar to those of Midha (2016), asserted that CA was manifested strongly through temporal dissociation and heightened enjoyment. We believe these similar findings might be attributed to the immersive nature of the used IT platforms in both studies. Saying that, our study findings indicated relatively stronger manifestation of CA especially through control dimension when compared to Midha's findings. We believe that this could be explained by the training context within which technology was used in our study. Participants in our study were provided with initial guidance on how to use the system, and as a result users' sense of control over their interaction with the system might have been more profound. Moreover, in our study we examined potential antecedents of CA such as personal innovativeness and computer playfulness where we found computer playfulness to have a significant relationship with CA; however, Midha's (2016) study did not examine predictors of CA.

Another example, Leong (2011) examined perceived social presence afforded by the system to users as well as users' interest in the subject matters offered through the online learning environment as predictors

\footnotetext{
${ }^{2}$ Sobel test was utilized to examine the statistical significance of the indirect effect. The indirect effect was found to be statistically significant at pvalue $<0.05$.
} 
for CA. While perceived social presence had a significant linear relationship with $C A$, interest in the subject matter did not predict CA. While we believe that system affordances such as social presence represent important CA predictors to examine, especially when the used technology does not offer the potential for offline interaction among its users, yet, we believe examining personality traits as CA predictors is important as well. Nonetheless, Leong (2011) did not examine how user's traits such as computer playfulness as well as personal innovativeness might influence the extent to which user might experience a state of cognitive absorption. Moreover, Leong (2011) examined a proximal consequence of CA which is users' satisfaction with online learning environment, while in our study we examined a distal consequence of CA which is the behavioral intention to use the technology in the future, which goes beyond satisfaction and represent an important outcome in the IS literature (Bhattacherjee, 2001). Finally, contrary to our results, Leong (2011) dropped CA curiosity dimension to improve model's fit results. We believe this might be due to the structured nature of traditional online learning environment which may not provide users with many opportunities for exploration. Similar results have been echoed by the findings of Saadé and Bahli (2005).

From a practical standpoint, our study suggests that training systems that promote a state of cognitive absorption can be feasible for imparting business process training. If it is not possible to use training systems such as simulations, corporations and managers can look towards tweaking the factors which encourage users to exercise their curiosity and enter a playful state of exploration. Specifically, placing relatively less emphasis on classroom type training and more on hands-on "learning by doing" can induce a flow-like state in the participants as well as encourage them to use the system. As corporations allocate resources to designing better training mechanisms, it would be worthwhile to invest in training using simulations as well as to measure and quantify the state of engagement across various training systems.

Our study can inform future studies interested in conceptual replication of Agarwal and Karahanna (2000) as well as managers interested in designing effective training. It would be beneficial for future studies to examine their context along three dimensions. (a) Nature of IT artifact: Target systems can be commonly used or can be novel. Depending on its nature, the potential for immersion, and interactivity, the ability to generate deep engagement may vary. (2) Context of use: If the focal system is mandatory, it may generate a sense of coercion on the participants. However, that may be counterbalanced by the nature of technology. (3) Demographics: If the target participants are millennials or digital natives, PEOU will likely have greater explanatory significance compared to PU. All three factors can interact, and it can change the impact that $\mathrm{CA}$ has on the $\mathrm{BI}$.

Further, future studies can be conducted in multiple stages. Although the results from the original study held in-general, it was not possible to dissect the role of cognitive absorption in game-like settings in great detail. To gain deeper insight into the role of deep engagement and absorption in simulations, the same model needs to be tested for business process training using traditional ERP systems as well as in simulation settings. Comparative analysis will provide a richer understanding of cognitive absorption's role in simulations and serious games. This study provides the first step towards such comparative research.

Finally, we would like to share several lessons learned with researchers interested in conducting conceptual replication research. Given the objective of the manuscript, we attempted to adhere to the operationalization of concepts used in the original study. As a result, in the current study, we adopted the measures used by Agarwal and Karahanna (2000) and modified the references to the focal IT artifact from World Wide Web to ERPSIM. We believe that future research should carefully consider how the context used for replication can inform the operationalization of the constructs used.

For example, researchers need to examine the domain specificity of the IT artifact in question and how items used to operationalize the constructs maps to it. To illustrate, the focal IT artifact in the original study (i.e. World Wide Web) was domain-general as the technology could be used for a wide array of purposes and as a result items used to capture users' perceived usefulness of the IT in question were domain-general as well (such as improved performance and effectiveness in college activities). We believe that future replications, especially in training contexts, need to operationalize the constructs and word items differently to directly connect to the investigated context as well as the level of domain specificity of the used technology. Thus, to assess the usefulness of the technology used in training researchers need to focus on the extent of perceived improvements in knowledge, skills, abilities, and understanding pertaining to the system that the users could attribute to the technology used in training.

To add, researchers also need to take into consideration possible scenarios for future use of the system/platform as they operationalize constructs used in their studies. For example, in training context, the operationalization of behavioral intentions to use the technology need to consider the availability of 
technology used in training to trainees in future. Even more, the behavioral intentions could be about using similar technology for future training. Lastly, behavioral intentions as a construct may not even be relevant in a mandatory use context whether for adopting technology in general or for training specifically.

\section{Conclusion}

Replicating established research in a new context is an important path to establish the boundaries of the conducted work and offer potential venues for its extension (Boudreau et al., 2001). In the current work, we examined Agarwal and Karahanna's (2000) work in the context of enactive learning. Our findings reflect the significance of technology use context as a boundary condition (Johns, 2006). Study results indicate the importance of cognitive absorption and the salience of perceived ease of use of training technology in fostering perceptions of technology usefulness and promoting its adoption. We hope that our findings guide the design of future computer-based simulation games for training purposes as well as future research pertaining to cognitive absorption.

\section{References}

Agarwal, R., \& Karahanna, E. (2000). Time flies when you're having fun: Cognitive absorption and beliefs about information technology usage. MIS Quarterly, 24(4), 665-694.

Bandura, A. (1989). Human agency in social cognitive theory. American Psychologist, 44(9), 1175-1184.

Bem, D. J. (1967). Self-perception: An alternative interpretation of cognitive dissonance phenomena. Psychological Review, 74(3), 183-200.

Bhattacherjee, A. (2001). Understanding information systems continuance: An expectation-confirmation model. MIS Quarterly, 25(3), 351-370.

Bollen, K.A. (1987). Total, direct, and indirect effects in structural equation models. Sociological Methodology, 17(1), 37-69.

Boughzala, I. (2014). Characterizing the serious game and assessing learning goals. Systèmes d'information \& Management, 19(3), 9-37.

Bozoglan, B., Demirer, V., \& Sahin, I. (2014). Problematic Internet use: Functions of use, cognitive absorption, and depression. Computers in Human Behavior, 37, 117-123.

Chin, W. W., Marcolin, B. L., \& Newsted, P. R. (2003). A partial least squares latent variable modeling approach for measuring interaction effects: Results from a Monte Carlo simulation study and an electronic-mail emotion/adoption study. Information Systems Research, 14(2), 189-217.

Chin, W. W. (2010). How to write up and report PLS analyses. In Vinzi, V., Chin, W., Henseler, J. \& Wang, H. (Eds.), Handbook of partial least squares (pp. 655-690). Springer, Berlin, Heidelberg.

Chin, W. W., Thatcher, J. B., \& Wrigth, R. T. (2012). Assessing common method bias: Problem with the ULMC technique. MIS Quarterly, 36(3), 1003-1019.

Chung, J. E., Park, N., Wang, H., Fulk, J., \& McLaughlin, M. (2010). Age differences in perceptions of online community participation among non-users: An extension of the Technology Acceptance Model. Computers in Human Behavior, 26(6), 1674-1684

Csikszentmihalyi, M. (1990). Flow: The psychology of optimal experience. NY: Harper \& Row.

Cronan, T. P., Léger, P.M., Robert, J., Babin, G., \& Charland, P. (2012). Comparing objective measures and perceptions of cognitive learning in an ERP simulation game. Simulation \& Gaming, 43(4), 461480.

Davis, F. D. (1989). Perceived usefulness, perceived ease of use, and user acceptance of information technology. MIS Quarterly, 13(3), 319-340.

Davis, F. D., Bagozzi, R. P., \& Warshaw, P. R. (1989). User acceptance of computer technology: A comparison of two theoretical models. Management Science, 35(8), 982-1003.

Fiedler, K. (2007). Construal level theory as an integrative framework for behavioral decision-making research and consumer psychology. Journal of Consumer Psychology, 17(2), 101-106. 
Fiedler, K., Jung, J., Wänke, M., \& Alexopoulos, T. (2012). On the relations between distinct aspects of psychological distance: An ecological basis of construal-level theory. Journal of Experimental Social Psychology, 48(5), 1014-1021.

Fornell, C., \& Larker, D.F. (1981). Structural equation models with unobservable variables and measurement error: Algebra and Statistics. Journal of Marketing Research, 18(3), 382-388.

Hess, T. J., McNab, A. L., \& Basoglu, K. A. (2014). Reliability Generalization of Perceived Ease of Use, Perceived Usefulness, and Behavioral Intentions. MIS Quarterly, 38(1), 1-29.

Johns, G. (2006). The essential impact of context on organizational behavior. Academy of Management Review, 31(2), 386-408.

Léger, P. M., Charland, P., Feldstein, H. D., Robert, J., Babin, G., \& Lyle, D. (2011). Business simulation training in information technology education: Guidelines for new approaches in IT training. Journal of Information Technology Education, 10(1), 28-51.

Léger, P. M., Cronan, T., Charland, P., Pellerin, R., Babin, G., \& Robert, J. (2012). Authentic OM problem solving in ERP context. International Journal of Operations and Production Management, 32(12), 13751394.

Léger, P. M., Davis, F. D., Cronan, T. P., \& Perret, J. (2014). Neurophysiological correlates of cognitive absorption in an enactive training context. Computers in Human Behavior, 34, 273-283.

Leong, P. (2011). Role of social presence and cognitive absorption in online learning environments. Distance Education, 32 (1), 5-28.

Liang, H., Saraf, N., Hu, Q., \& Xue, Y. (2007). Assimilation of enterprise systems: The effect of institutional pressures and the mediating role of top management. MIS Quarterly, 31(1), 59-87.

Malone, T. W. (1981). Toward a theory of intrinsically motivating instruction. Cognitive Science, 5(4), 333369.

Mayo, M. J. (2007). Games for science and engineering education. Communications of the ACM, 50(7), 3035.

Midha, V. (2016). Cognitive Absorption: An Empirical Examination of 3-D Immersive Virtual World Users. AIS Transactions on Replication Research, 2(1), 1-11.

Nunnally, J. C., \& Bernstein, I. H. (1978). Psychometric Testing. New York: McGraw.

Pavlou, P. A., Liang, H., \& Xue, Y. (2006). Understanding and mitigating uncertainty in online environments: A principal-agent perspective. MIS Quarterly 31(1), 105-136.

Podsakoff, P. M., MacKenzie, S. B., Lee, J. Y., \& Podsakoff, N. P. (2003). Common method biases in behavioral research: A critical review of the literature and recommended remedies. Journal of Applied Psychology, 88(5), 879-903.

Podsakoff, P. M., \& Organ, D. W. (1986). Self-reports in organizational research: Problems and prospects. Journal of Management, 12(4), 531-544.

Saadé, R., \& Bahli, B. (2005). The impact of cognitive absorption on perceived usefulness and perceived ease of use in on-line learning: An extension of the technology acceptance model. Information \& Management, 42(2), 317-327.

Sanchez, J. I., Korbin, W. P., \& Viscarra, D. M. (1995). Corporate support in the aftermath of a natural disaster: Effects on employee strains. Academy of Management Journal, 38(2), 504-521.

Sein, M. K., Bostrom, R. P., \& Olfman, L. (1999). Rethinking end-user training strategy: Applying a hierarchical knowledge-level model. Journal of End User Computing, 11(1), 32-39.

Sitzmann, T. (2011). A meta-analytic examination of the instructional effectiveness of computer-based simulation games. Personnel Psychology, 64(2), 489-528.

Trope, Y., \& Liberman, N. (2010). Construal-level theory of psychological distance. Psychological Review, 117(2), 440-463. 
Venkatesh, V. (1999). Creation of favorable user perceptions: exploring the role of intrinsic motivation. MIS Quarterly, 23(2), 239-260.

Venkatesh, V., \& Davis, F. D. (2000). A theoretical extension of the technology acceptance model: Four longitudinal field studies. Management Science, 46(2), 186-204.

Webster, J., \& Ho, H. (1997). Audience engagement in multimedia presentations. ACM SIGMIS Database, 28(2), 63-77.

Webster, J., \& Martocchio, J. J. (1992). Microcomputer playfulness: Development of a measure with workplace implications. MIS Quarterly, 16(2), 201-226. 


\section{Appendix A: ERPSIM Job Aid}

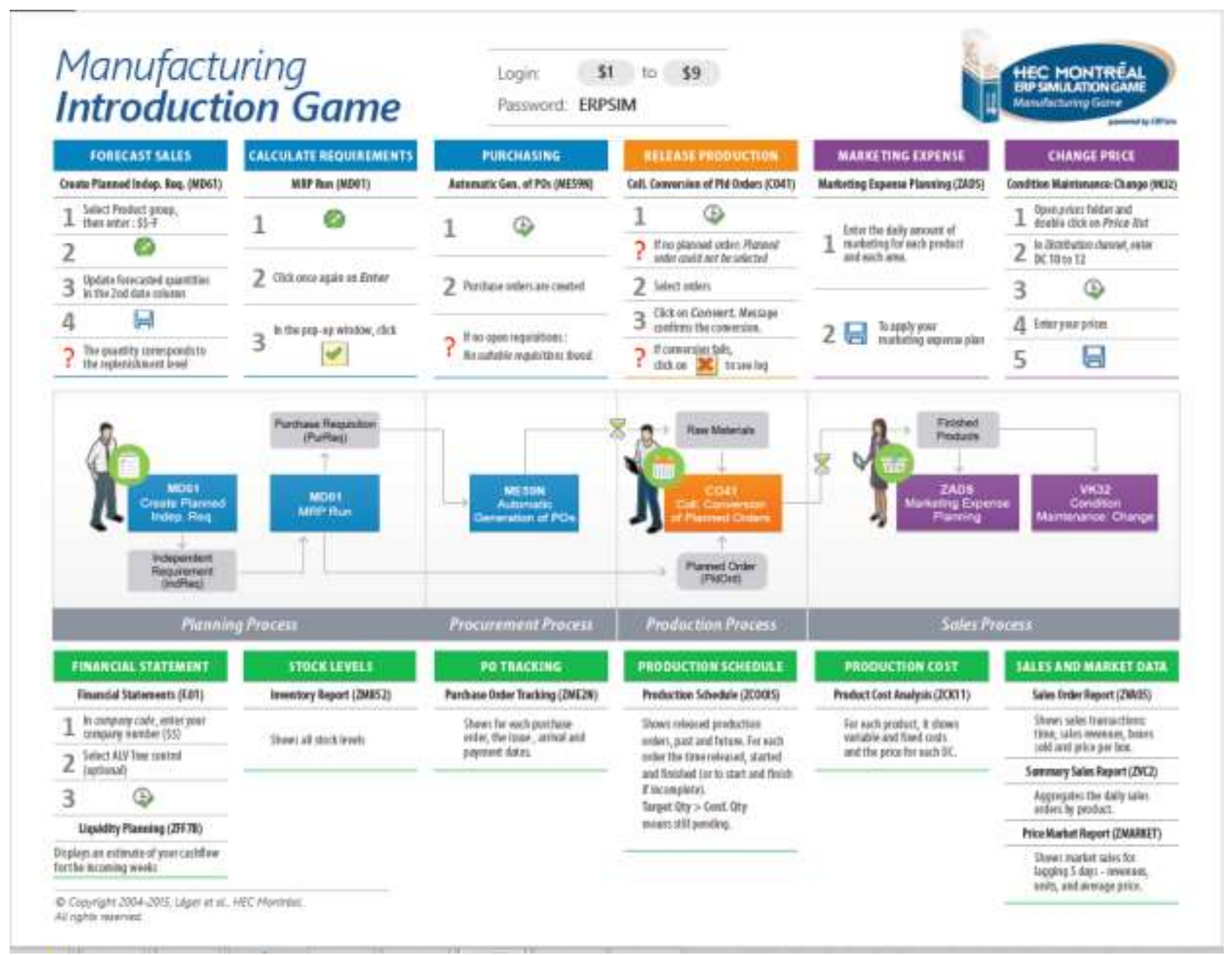

Figure A. Job Aid 


\section{Appendix B: Construct Items}

\begin{tabular}{|c|c|c|c|c|}
\hline \multicolumn{5}{|c|}{ Table B. Construct Items } \\
\hline Construct & Indicator & Item & Mean & SD \\
\hline \multirow{5}{*}{$\begin{array}{l}\text { CA: Temporal } \\
\text { Dissociation }\end{array}$} & TD1 & $\begin{array}{l}\text { Time appears to go by very quickly when I am using the ERP } \\
\text { simulation }\end{array}$ & 5.18 & 1.40 \\
\hline & TD2 & Sometimes I lose track of time when I am using the ERP simulation & 5.12 & 1.39 \\
\hline & TD3 & Time flies when I am using the ERP simulation & 5.11 & 1.35 \\
\hline & TD4 & $\begin{array}{l}\text { Most times when I get on the ERP simulation, I end up spending } \\
\text { more time that I had planned }\end{array}$ & 5.15 & 1.40 \\
\hline & TD5 & I often spend more time on the ERP simulation than I had intended. & 4.36 & 1.50 \\
\hline \multirow{5}{*}{$\begin{array}{l}\text { CA: Focused } \\
\text { Immersion }\end{array}$} & $\mathrm{Fl1}$ & $\begin{array}{l}\text { While using the ERP simulation, I am able to block out most other } \\
\text { distractions. }\end{array}$ & 5.01 & 1.49 \\
\hline & $\mathrm{Fl} 2$ & While using the ERP simulation, I am absorbed in what I am doing, & 4.88 & 1.37 \\
\hline & $\mathrm{FI} 3$ & $\begin{array}{l}\text { While on the ERP simulation, I am immersed in the task I am } \\
\text { performing. }\end{array}$ & 4.90 & 1.45 \\
\hline & $\mathrm{FI} 4$ & $\begin{array}{l}\text { When on the ERP simulation, I get distracted by other attentions } \\
\text { very easily, }\end{array}$ & 5.01 & 1.39 \\
\hline & $\mathrm{FI5}$ & $\begin{array}{l}\text { While on the ERP simulation, my attention does not get diverted } \\
\text { very easily. }\end{array}$ & 3.80 & 0.66 \\
\hline \multirow{4}{*}{$\begin{array}{l}\text { CA: Heightened } \\
\text { Enjoyment }\end{array}$} & HE1 & I have fun interacting with the ERP simulation. & 4.99 & 1.42 \\
\hline & HE2 & Using the ERP simulation provides me with a lot of enjoyment- & 4.38 & 1.62 \\
\hline & HE3 & I enjoy using the ERP simulation. & 4.78 & 1.50 \\
\hline & HE4 & Using the ERP simulation bores me. & 4.95 & 1.42 \\
\hline \multirow{3}{*}{ CA: Control } & $\mathrm{CO} 1$ & When using the ERP simulation, I feel in control & 5.07 & 1.27 \\
\hline & $\mathrm{CO} 2$ & $\begin{array}{l}\text { I feel that I have no control over my interaction with the ERP } \\
\text { simulation }\end{array}$ & 5.03 & 1.31 \\
\hline & $\mathrm{CO} 3$ & The ERP simulation allows me to control my computer interaction & 5.13 & 1.30 \\
\hline \multirow{3}{*}{ CA: Curiosity } & CU1 & Using the ERP simulation excites my curiosity & 4.96 & 1.39 \\
\hline & CU2 & Interacting with the ERP simulation makes me curious & 5.30 & 1.28 \\
\hline & CU3 & Using the ERP simulation arouses my imagination & 5.02 & 1.40 \\
\hline \multirow{3}{*}{$\begin{array}{l}\text { Personal } \\
\text { Innovativeness }\end{array}$} & PIIT1 & $\begin{array}{l}\text { If I heard about a new information technology, I would look for ways } \\
\text { to experiment with it. }\end{array}$ & 5.00 & 1.39 \\
\hline & PIIT2 & In general, I am hesitant to try out new information technologies & 5.64 & 1.12 \\
\hline & PIIT3 & $\begin{array}{l}\text { Among my peers, I am usually the first to try out new information } \\
\text { technologies }\end{array}$ & 5.41 & 1.21 \\
\hline
\end{tabular}




\begin{tabular}{|c|c|c|c|c|}
\hline \multicolumn{5}{|c|}{ Construct Items (Continued) } \\
\hline Construct & Indicator & Item & Mean & SD \\
\hline $\begin{array}{c}\text { Personal } \\
\text { Innovativeness }\end{array}$ & PIIT4 & I like to experiment with new information technologies & 5.61 & 1.18 \\
\hline \multirow{7}{*}{$\begin{array}{l}\text { Computer } \\
\text { Playfulness }\end{array}$} & CPL1 & When using the ERP simulation I am Spontaneous & 5.75 & 1.17 \\
\hline & CPL2 & When using the ERP simulation I am Imaginative. & 5.64 & 1.16 \\
\hline & CPL3 & When using the ERP simulation I am Flexible & 5.70 & 1.18 \\
\hline & CPL4 & When using the ERP simulation I am Creative & 5.57 & 1.23 \\
\hline & CPL5 & When using the ERP simulation I am Playful & 5.68 & 1.14 \\
\hline & CPL6 & When using the ERP simulation I am Original & 5.45 & 1.31 \\
\hline & CPL7 & When using the ERP simulation I am Inventive & 5.31 & 1.24 \\
\hline \multirow{5}{*}{ Self-Efficacy } & SE1 & $\begin{array}{l}\text { I could complete my task using a software package If there was no } \\
\text { one around to tell me what to do as I go }\end{array}$ & 5.80 & 1.08 \\
\hline & SE2 & $\begin{array}{l}\text { I could complete my task using a software package I had never used } \\
\text { a package like this before }\end{array}$ & 5.73 & 1.17 \\
\hline & SE3 & $\begin{array}{l}\text { I could complete my task using a software package If I had only the } \\
\text { software manuals for reference }\end{array}$ & 5.56 & 1.21 \\
\hline & SE4 & $\begin{array}{l}\text { I could complete my task using a software package If I had seen } \\
\text { someone else using it before trying it myself }\end{array}$ & 5.40 & 1.42 \\
\hline & SE5 & $\begin{array}{l}\text { I could complete my task using a software package If I could call } \\
\text { someone for help if I got stuck (Dropped) }\end{array}$ & 4.76 & 1.40 \\
\hline \multirow{4}{*}{$\begin{array}{l}\text { Perceived } \\
\text { Usefulness }\end{array}$} & PU1 & Using the ERP simulation enhances my effectiveness in college & 5.45 & 1.38 \\
\hline & PU2 & Using the ERP simulation enhances my productivity & 5.43 & 1.35 \\
\hline & PU3 & I find the ERP simulation useful in my college activities & 5.48 & 1.34 \\
\hline & PU4 & Using the ERP simulation improves my performance in college & 5.49 & 1.33 \\
\hline \multirow{4}{*}{$\begin{array}{l}\text { Perceived Ease of } \\
\text { Use }\end{array}$} & PEOU1 & Learning to operate the ERP simulation is easy for me & 5.17 & 1.29 \\
\hline & PEOU2 & I find it easy to get the ERP simulation do what I want it to do & 4.86 & 1.46 \\
\hline & PEOU3 & It is easy for me to become skillful at using the ERP simulation & 5.14 & 1.37 \\
\hline & PEOU4 & I find the ERP simulation easy to use & 4.59 & 1.63 \\
\hline \multirow{3}{*}{ Behavioral Intention } & $\mathrm{B} 11$ & $\begin{array}{l}\text { I intend to use the ERP simulation to learn about interconnected } \\
\text { business processes }\end{array}$ & 5.23 & 1.30 \\
\hline & $\mathrm{BI} 2$ & $\begin{array}{l}\text { To learn about the complex business processes, I intend to use the } \\
\text { ERP simulation }\end{array}$ & 5.26 & 1.27 \\
\hline & $\mathrm{BI} 3$ & $\begin{array}{l}\text { I expect to my use of the ERP simulation to continue in future for } \\
\text { exploring complex business processes. }\end{array}$ & 5.50 & 1.13 \\
\hline
\end{tabular}

Note: CA: Cognitive Absorption. TD5, FI1, FI5, HE2, PIIT4, CPL6, CPL7, and SE5 were dropped due to poor loading index. 


\section{About the Authors}

Vishal Shah is an Assistant Professor of Information Systems at Central Michigan University. His research interests include IS pedagogy, social media, IT and learning, game-based learning, and telemedicine. He has published in leading IS conferences such as Americas Conference on Information Systems, International Association for Computer and Information Systems, and Annual Meeting of the Decision Since Institute. His research has also appeared in the Journal of Information Systems Education and Journal of Education for business.

Amr Soror is an Assistant Professor of Information Systems and Decision Sciences at the College of Business and Economics, California State University, Fullerton. His research focuses on examining the potential role of IT use in the inhibition as well as the facilitation of end users goal-directed behaviors. He has authored refereed publications in prominent IS journals and conferences such as Information Systems Journal, Computers in Human Behavior, Americas Conference on Information Systems, Hawaii International Conference on System Sciences, and Annual Meeting of the Decision Since Institute. He serves as a Review Editor for the Frontiers in Psychology, psychopathology section

Copyright @ 2019 by the Association for Information Systems. Permission to make digital or hard copies of all or part of this work for personal or classroom use is granted without fee provided that copies are not made or distributed for profit or commercial advantage and that copies bear this notice and full citation on the first page. Copyright for components of this work owned by others than the Association for Information Systems must be honored. Abstracting with credit is permitted. To copy otherwise, to republish, to post on servers, or to redistribute to lists requires prior specific permission and/or fee. Request permission to publish from: AIS Administrative Office, P.O. Box 2712 Atlanta, GA, 30301-2712 Attn: Reprints or via e-mail from ais@aisnet.org. 